\title{
Prediction of Ultimate Load of Rectangular CFST Columns Using Interpretable Machine Learning Method
}

\author{
Tien-Thinh Le $\mathbb{D}^{1,2}$ and Hieu Chi Phan $\mathbb{D}^{3}$ \\ ${ }^{1}$ Faculty of Mechanical Engineering and Mechatronics, PHENIKAA University, Yen Nghia, Ha Dong, Hanoi 12116, Vietnam \\ ${ }^{2}$ PHENIKAA Research and Technology Institute (PRATI), A\&A Green Phoenix Group JSC, No. 167, Hoang Ngan, Trung Hoa, \\ Cau Giay, Hanoi 11313, Vietnam \\ ${ }^{3}$ Le Quy Don Technical University, 236 Hoang Quoc Viet, Hanoi 100000, Vietnam
}

Correspondence should be addressed to Tien-Thinh Le; thinh.letien@phenikaa-uni.edu.vn

Received 11 August 2020; Revised 5 December 2020; Accepted 10 December 2020; Published 24 December 2020

Academic Editor: Rizal Rashid

Copyright (c) 2020 Tien-Thinh Le and Hieu Chi Phan. This is an open access article distributed under the Creative Commons Attribution License, which permits unrestricted use, distribution, and reproduction in any medium, provided the original work is properly cited.

\begin{abstract}
The ultimate compressive load of concrete-filled steel tubular (CFST) structural members is recognized as one of the most important engineering parameters for the design of such composite structures. Therefore, this paper deals with the prediction of ultimate load of rectangular CFST structural members using the adaptive neurofuzzy inference system (ANFIS) surrogate model. To this end, compression test data on CFST members were extracted from the available literature, including: (i) the mechanical properties of the constituent materials (i.e., steel's yield strength and concrete's compressive strength) and (ii) the geometric parameters (i.e., column length, width and height of cross section, and steel tube thickness). The ultimate load is the output response of the problem. The ANFIS model was trained using a hybrid of the least-squares and backpropagation gradient descent method. Quality assessment criteria such as coefficient of determination $\left(R^{2}\right)$, root mean square error (RMSE), and slope of linear regression were used for error measurements. A 11-fold cross-validation technique was employed to evaluate the performance of the model. Results showed that for the training process, the average performance was as follows: $R^{2}$, RMSE, and slope were 0.9861 , $89.83 \mathrm{kN}$, and 0.9861 , respectively. For the validating process, the average performance was as follows: $R^{2}$, RMSE, and slope were $0.9637,140.242 \mathrm{kN}$, and 0.9806 , respectively. Therefore, the ANFIS model may be considered valid because it performs well in predicting ultimate load using the validated data. Moreover, partial dependence (PD) analysis was employed to interpret the "black-box" ANFIS model. It is observed that PD enabled us to locally track the influence of each input variable on the output response. Besides reliable prediction of ultimate load, ANFIS can also provide maps of ultimate load. Finally, the ANFIS model developed in this study was compared with other works in the literature, showing that the ANFIS model could improve the accuracy of ultimate load prediction, in comparison to previously published results.
\end{abstract}

\section{Introduction}

Concrete-filled steel tubular (CFST) structural members exhibit very interesting properties, as they combine the advantages of the two constituent materials. In such composite structures, the tensile strength of the steel tube and the compressive strength of the concrete core combine to enhance many properties and structural performances of the members, such as strength $[1,2]$, ductility $[3,4]$, loadbearing capacity $[5,6]$, fire resistance $[7,8]$, earthquake resistance $[9,10]$, energy absorption capacity $[11,12]$, and so on. To date, rectangular CFST members have been employed in many constructions such as buildings, bridges, and underground stations because of their strong moment resistance [13] and simple beam-column joints [10, 14]. Moreover, with a given sectional size, rectangular CFST members exhibit greater stiffness than circular or elliptical members [15-17]. Although the design process for rectangular CFST columns is set forth in many current codes such as Eurocode 4 [18], AISC [19], and ACI [20], up until now, the axial behavior of rectangular CFST members has received crucial attention from researchers/engineers. The main 
reason is that current codes do not necessarily have the capacity to take account of different material strengths or ranges of geometrical dimension [21-24]. As indicated in Xiong et al. [22], Eurocode 4 is only applicable to CFST members with steel yield strength in the range of $235 \mathrm{MPa}$ to $460 \mathrm{MPa}$, whereas concrete cylinder compressive strength varies from $20 \mathrm{MPa}$ to $50 \mathrm{MPa}$. In the case of AISC, the yield strength of steel may vary up to $525 \mathrm{MPa}$, whereas the cylinder compressive strength of concrete may be up to $70 \mathrm{MPa}$. As axial compression of composite columns is a complex problem, there are a range of questions which still need to be investigated. Indeed, many variables are involved in this problem, including geometrical parameters and mechanical properties of the constituent materials [25]. As CFST members are composite structures, the relationship between variables and macroscopic properties must be established in order to accurately investigate their mechanical performance and failure. Therefore, there are many ongoing theoretical, numerical, and experimental studies to obtain a better understanding of the axial behavior of rectangular CFST members.

Experimental investigations are normally the best approach to study the behavior of CFST members. However, experimental design is often carried out subject to a small range of parameters, leading to a limited number of specimens [13]. In addition, extensive experimental studies have hitherto been costly and time-consuming $[25,26]$. In terms of numerical modeling, An and Han [27] put forward a finite element (FE) model for investigating CFST members under both compression and bending. The model developed has been used for a parametric study of the parameters influencing the strength of the composite structures. In another study, Zhou and Han [28] also employed the FE method to model the fire behavior of CFST members. Nguyen et al. [29] developed a FE model taking account of the interface properties between steel and concrete in CFST columns. The FE technique has also been used in many other works to numerically model the axial behavior of CFST columns [30-33]. There are also several empirical formulae in the available literature such as Ding et al. [1], Wang et al. [23], Tran et al., [21] and Han et al. [34] for predicting the ultimate load of rectangular CFST members. However, these equations have been derived on the basis of simple assumptions and observations. Consequently, it is not guaranteed that these models will be applicable. The aforesaid studies have provided significant contributions to progress in modeling and prediction of axial behavior of CFST members. However, there is a need for a more efficient and robust manner to better characterize the mechanical performance of such composite structures, including the influence of variables on their macroscopic properties.

Artificial intelligence- (AI-) based models have received significant attention from researchers all around the world, especially in civil engineering-related problems [35-46]. For single-material structures, various studies have set out to predict (i) the buckling capacity of steel members [47-50] and (ii) the compressive strength of concrete [51-55]. For composite structures, Sarir et al. [36] proposed a tree-based and whale optimization model for predicting the load- bearing capacity of circular CFST members. In addition, Ahmadi et al. $[56,57]$ applied an artificial neural network to predict the axial capacity of short CFST columns. Güneyisi et al. $[58,59]$ derived a gene expression programming model to predict the load-bearing capacity of circular CFST members. The performance of such a model has been shown to be better higher than the formulae found in the preexisting literature. Al-Khaleefi et al. [60] introduced a neural network model for studying the fire resistance of CFST members, taking account of different structural, material factors, and loading conditions. Moon et al. [61] have successfully developed a fuzzy logic model for predicting the strength of circular CFST stub columns. The study investigated the effect of concrete confinement on the axial capacity of the columns. Despite the importance of rectangular CFST columns, most AI-based studies so far have concentrated on members with a circular cross section [36, 58, 61]. Most recently, a few studies have been published involving square cross sections. Ren et al. [35] employed support vector machine and particle swarm optimization to investigate the axial capacity of square CFST members. Tran et al. [21] developed a neural network-based model to predict the load-bearing capacity of square CFST columns. Therefore, more investigations are required to assess the potential applications of AI-based models for studying axial behavior of rectangular CFST columns, especially in the highly topical context of high-rise construction.

This work is devoted to the prediction and influence of variables on the ultimate load of rectangular CFST columns, using the adaptive neurofuzzy inference system (ANFIS) model. It should be noted that ANFIS has not yet been used, in the literature, for studying rectangular CFST members and highlighting the influence of variables on the macroscopic properties. The reason for selecting the interpretable ANFIS technique is described in Section 2.2. Section 2.1 introduces the database used to train and validate the developed ANFIS model. In Section 2.2, details of considered variables and reasons for selection are presented. Section 3 presents the phase of training and 11-fold cross-validation of the ANFIS model, together with regression analysis. Finally, partial dependence (PD) analysis was applied in order to interpret the "black-box" ANFIS model, which elucidated the influence of each variable on the output response.

\section{Materials and Methods}

2.1. Database. As set forth in the literature, the experimental process followed the steps below [35, 62-64]:

(1) Design of specimens.

(2) Manufacture of steel tube (cold-formed or welded).

(3) Manufacture of concrete.

(4) Assembly of composite structural members.

(5) Loading and measurement (see Figure 1 for schematic description of the test).

In this work, 99 compression tests on CFST members were collected from the literature (data summarized in Table 1). Table 2 shows the initial analysis, including 

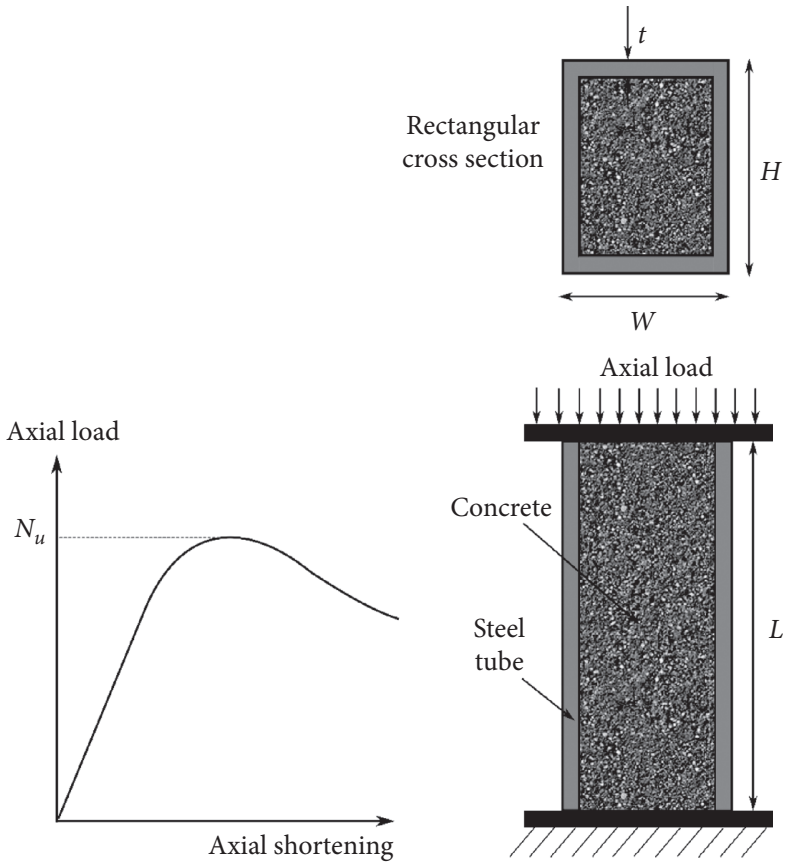

$W$

Axial load

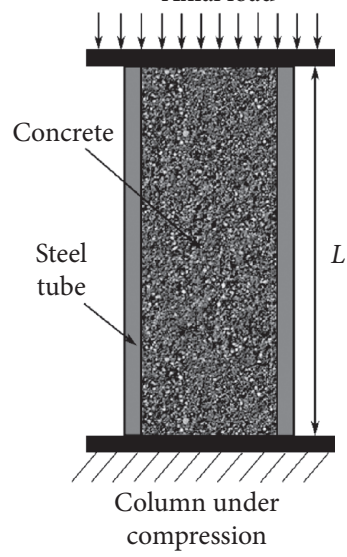

Figure 1: Diagram of concrete-filled steel tube under compression including frontal view and cross-sectional view.

TABLE 1: Summary of the dataset used in this study.

\begin{tabular}{|c|c|c|c|c|c|c|c|c|c|c|c|c|}
\hline$N^{\circ}$ & 1 & 2 & 3 & 4 & 5 & 6 & 7 & 8 & 9 & 10 & 11 & - \\
\hline Reference & $\begin{array}{c}\text { Bridge } \\
\text { [65] }\end{array}$ & $\begin{array}{l}\text { Du } \\
\text { et al. } \\
{[63]}\end{array}$ & $\begin{array}{l}\mathrm{Du} \\
\text { et al. } \\
{[66]}\end{array}$ & $\begin{array}{l}\text { Ghannam } \\
\text { et al. [64] }\end{array}$ & $\begin{array}{l}\text { Han } \\
{[67]}\end{array}$ & $\begin{array}{l}\text { Han } \\
\text { and } \\
\text { Yang } \\
{[68]}\end{array}$ & $\begin{array}{c}\text { Han } \\
\text { and } \\
\text { Yao [2] }\end{array}$ & $\begin{array}{l}\text { Lin } \\
{[69]}\end{array}$ & $\begin{array}{c}\text { Schneider } \\
{[70]}\end{array}$ & $\begin{array}{l}\text { Shakir- } \\
\text { Khalil and } \\
\text { Mouli [71] }\end{array}$ & $\begin{array}{c}\text { Shakir-Khalil } \\
\text { and Zeghiche } \\
\text { [72] }\end{array}$ & Total \\
\hline $\begin{array}{l}\text { Number of } \\
\text { tests }\end{array}$ & 1 & 5 & 8 & 12 & 20 & 4 & 19 & 6 & 9 & 14 & 1 & 99 \\
\hline $\begin{array}{l}\text { Proportion } \\
(\%)\end{array}$ & 1 & 5.1 & 8.1 & 12.1 & 20.2 & 4 & 19.2 & 6.1 & 9.1 & 14.1 & 1 & 100 \\
\hline
\end{tabular}

TABLE 2: Initial statistical analysis of variables in the database.

\begin{tabular}{|c|c|c|c|c|c|c|c|}
\hline Parameter & Column's length & $\begin{array}{l}\text { Steel tube } \\
\text { thickness }\end{array}$ & $\begin{array}{l}\text { Cross section } \\
\text { height }\end{array}$ & $\begin{array}{l}\text { Cross section } \\
\text { width }\end{array}$ & $\begin{array}{l}\text { Steel yield } \\
\text { stress }\end{array}$ & $\begin{array}{l}\text { Concrete compressive } \\
\text { strength }\end{array}$ & $\begin{array}{l}\text { Ultimate } \\
\text { load }\end{array}$ \\
\hline Notation & $L$ & $t$ & $H$ & $W$ & $f_{y}$ & $f_{c}^{\prime}$ & $N_{u}$ \\
\hline Unit & $\mathrm{mm}$ & $\mathrm{mm}$ & $\mathrm{mm}$ & $\mathrm{mm}$ & $\mathrm{MPa}$ & $\mathrm{MPa}$ & $\mathrm{kN}$ \\
\hline Type & Predictor & Predictor & Predictor & Predictor & Predictor & Predictor & Target \\
\hline Minimum & 100 & 0.7 & 90 & 60 & 194 & 7.9 & 490 \\
\hline Median & 545 & 3 & 150 & 100 & 340.1 & 33.74 & 1006 \\
\hline Maximum & 3050 & 10.01 & 360 & 240 & 514.53 & 46.85 & 3575 \\
\hline Average & 869.23 & 4.12 & 163.38 & 110.94 & 329.09 & 31.12 & 1267.61 \\
\hline Standard deviation & 772.12 & 1.97 & 53.01 & 35.63 & 78.73 & 12.21 & 768.72 \\
\hline $\mathrm{CV}^{*}$ & 88.83 & 47.84 & 32.45 & 32.12 & 23.92 & 39.23 & 60.64 \\
\hline
\end{tabular}

${ }^{*} \mathrm{CV}$ stands for coefficient of variation (\%).

notation, unit, minimum, maximum, average, standard deviation, and coefficient of variation of all variables in the database. Those variables are height of cross section $H$, width of cross section $W$, thickness of steel tube $t$, length of column
$L$, yield stress of steel $f_{y}$, compressive strength of concrete $f_{c}^{\prime}$, and ultimate load $N_{u}$, respectively (see Figure 1 for geometric description). A hypothesis was made such that the influence of initial geometric imperfections and residual 
stress was negligible compared to the major geometric parameters and mechanical properties of the constituent materials [36]. In addition, there is no steel reinforcement in the concrete core or the tube (i.e., stiffeners). Finally, only uniaxial monotonic compression tests were considered.

\subsection{Machine Learning Method: Adaptive Neurofuzzy Infer-} ence System. The adaptive neurofuzzy inference system (ANFIS) is a combination between the learning rules of adaptive networks and a fuzzy inference system, designed to make precise predictions in many aspects of human knowledge. The inference system is based on if-then rules [73], while the adaptive networks system is based on the gradient descent and the chain rule introduced in [74].

Figure 2 shows the basic structure of the ANFIS algorithm in a simplified case with only two inputs. In more complicated cases with a large number of inputs, the algorithm is straightforward. Basically, the ANFIS structure consists of five main layers (shown in Figure 2), each layer containing node functions of the same function family [75]. The layers are as follows [41]:

Layer 1. Each node in this layer corresponds to a node function, which can be chosen to be bell-shaped with minimum value equal to 0 and maximum value equal to 1 -for example, the Gaussian function such that

$$
\mu A_{i}(x)=\exp \left[-\left(\frac{x-a_{i}}{b_{i}}\right)^{2}\right]
$$

where $x$ is the problem input and $a_{i}$ and $b_{i}$ are input parameters.

In fact, any continuous and differentiable function can be chosen for the nodes in this layer.

Layer 2. Each node in this layer is a node function that multiplies the incoming inputs and sends the results to the next layer:

$$
w_{i}=\mu C_{i}^{1}\left(x_{1}\right) \times \mu C_{i}^{2}\left(x_{2}\right) \times \cdots \mu C_{i}^{n}\left(x_{n}\right) .
$$

Layer 3. Each node in this layer computes the ratio between the $i$-th rule's firing strength and the sum of all rules' firing strength:

$$
\bar{w}_{i}=\frac{w_{i}}{\sum_{k=1}^{n} w_{k}} .
$$

Layer 4. Each node in this layer is a node function chosen such that

$$
f_{i}=\bar{w}_{i}\left(c_{0}+\sum_{k=1}^{n} c_{k} X_{k}\right) .
$$

Layer 5. The circle node in this layer calculates the sum of all incoming results and exports the overall output:

$$
\text { overall ouput }=\sum_{i} \bar{w}_{i} f_{i} \text {. }
$$

It is interesting to notice that ANFIS was especially helpful in various engineering applications where conventional techniques failed or the latter were too complicated to be used [76]. The crucial advantages of the ANFIS model are highlighted as follows: (i) simplicity, (ii) computational efficiency, and (iii) adaptability [77], compared with other machine learning methods. Indeed, ANFIS constructs an inout mapping based on human knowledge and generates output responses by using backpropagation algorithm [78]. After training, validating, and testing, the ANFIS model can be employed to recognize data that were semblable to any of the specimens exposed during the training process. The ANFIS model exhibits better effectiveness than the two lone models (i.e., artificial neural network and fuzzy logic), as proved in many studies such as Aditya et al. [79] and Nayak et al. [80]. Presently, ANFIS has been more and more employed in the field of structural engineering [78, 81-85]. The investigations explored that the ANFIS model yielded superior accuracy compared with other machine learning techniques and experimental data points. However, the ANFIS model suffers from a number of limitations; for instance, it is weak in finding the optimal firing strength $[86,87]$. By using several metaheuristic optimization techniques such as genetic algorithm or simulated annealing as examples in $[88,89]$, it is possible to search for and better determine the firing strengths of parameters.

2.3. K-Fold Cross-Validation. In this work, the K-fold crossvalidation technique was employed to evaluate the performance of the ANFIS model. It is interesting to notice that such a technique could reduce the overfitting problem as well as the effect of randomness of training and test data [90]. Moreover, this technique is also efficient in case of small dataset [91]. Various investigations have pointed out that 10fold is the optimal number of folds that allows obtaining a suitable result within an acceptable range of error [90, 92]. Therefore, in this study, regarding the number of data points, the 11-fold cross-validation technique was adopted to evaluate the efficiency of the ANFIS model, following the procedure described in Bui et al. [92]. The diagram of the 11fold cross-validation technique is shown in Figure 3. More precisely, the procedure is as follows. The index of 99 data in the initial dataset was randomly selected and split into 11 different subsets or folds. In the first run, the first fold was used to test the model while the 10 remaining subsets were employed for training the model. Hence, the ANFIS model was trained 11 times using 11 different training and testing datasets, i.e., all data points were used in both training and testing phases. In each run, the performance of the model was recorded in order to evaluate the overall performance of the model. 

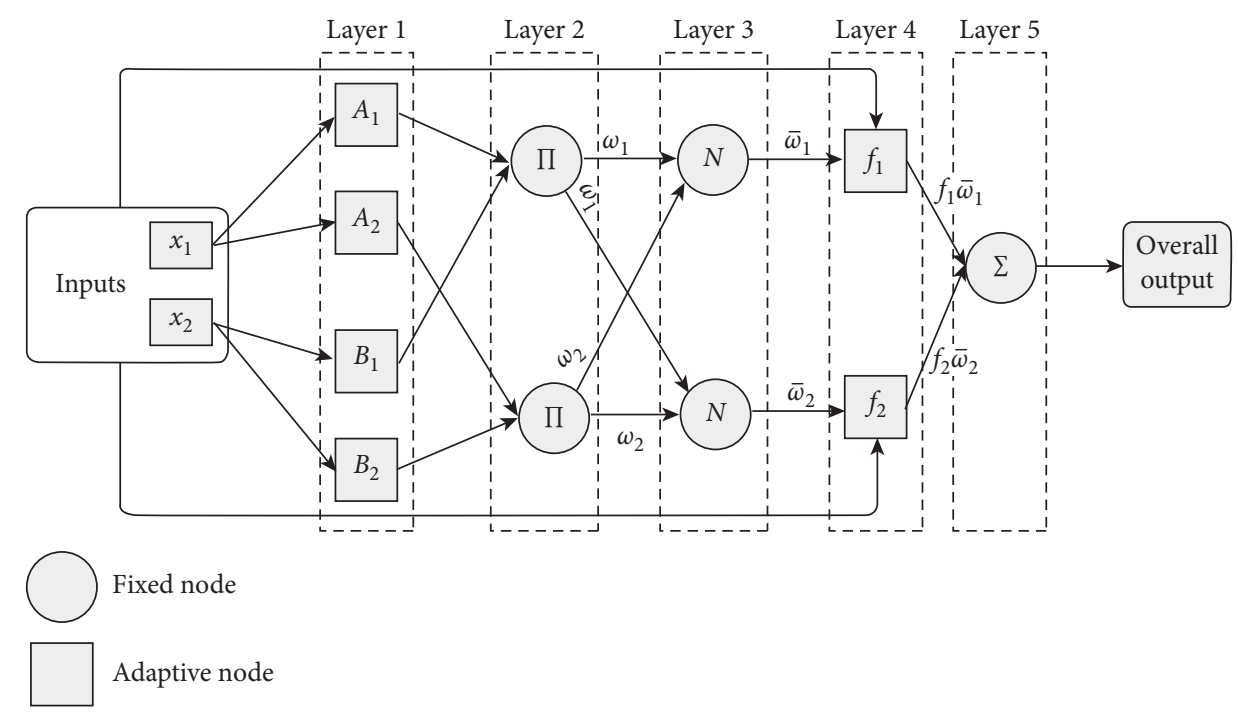

FIGURE 2: Illustration of basic ANFIS structure with two input parameters.

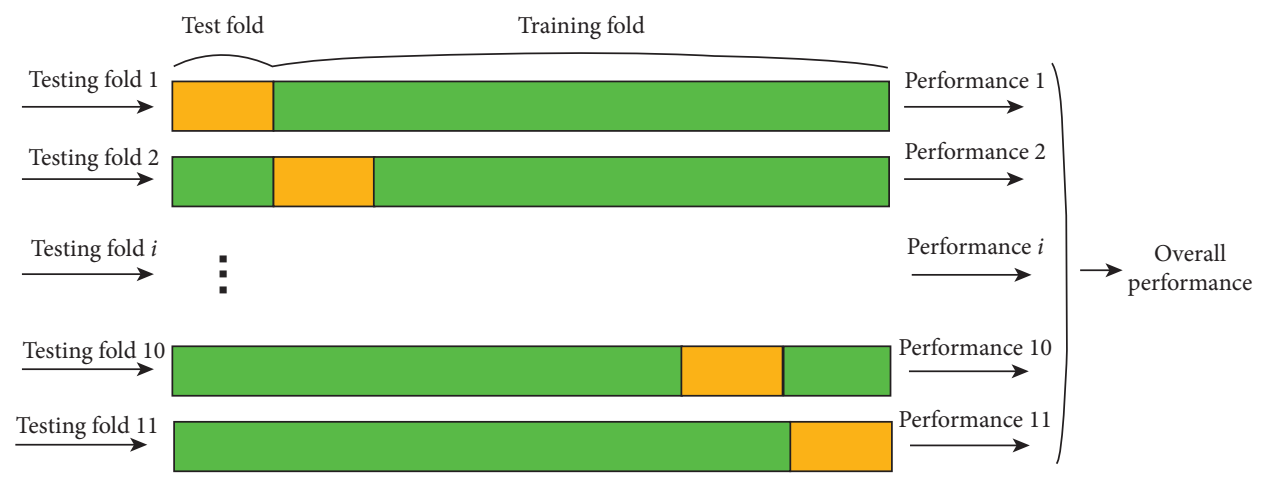

FIGURE 3: Diagram of 11-fold cross-validation.

2.4. Quality Assessment Criteria. In the present work, statistical criteria-namely, coefficient of determination $\left(R^{2}\right)$, mean absolute error (MAE), and root mean square error (RMSE) - have been used in order to validate and test the AI models developed. $R^{2}$ allows us to identify the statistical relationship between two pieces of data. This measurement of the linear correlation yields a value between 0 and 1 inclusive, where 0 is no correlation and 1 is total correlation. $R^{2}$ can be calculated using the following equation [93-97]:

$$
R^{2}=\frac{\sum_{k=1}^{N}\left(p_{k}-\bar{p}\right)\left(w_{k}-\bar{w}\right)}{\sqrt{\sum_{k=1}^{N}\left(p_{k}-\bar{p}\right)^{2} \sum_{k=1}^{N}\left(w_{k}-\bar{w}\right)^{2}}}
$$

where $N$ is the number of the observations and $p_{k}$ and $\bar{p}$ are the predicted and mean predicted values while $w_{k}$ and $\bar{w}$ are measured and mean measured values of ultimate load, respectively $(k=1: N)$. In the case of MAE, a low MAE indicates good accuracy of prediction output using the models. MAE can be calculated using the following equation [98-101]:

$$
\mathrm{MAE}=\frac{\sum_{k=1}^{N}\left|p_{k}-w_{k}\right|}{N}
$$

where $p_{k}$ and $w_{k}$ are the predicted and observed values, respectively $(k=1: N)$. The formulation of RMSE is described by the following equation [102-106]:

$$
\mathrm{RMSE}=\sqrt{\frac{1}{N} \sum_{k=1}^{N}\left(p_{k}-w_{k}\right)^{2}}
$$

Finally, the slope criterion is defined as the slope of the linear regression fit between predicted and observed vectors.

2.5. Interpretation of Machine Learning Method: Partial Dependence Analysis. In this work, partial dependence (PD) analysis was used to interpret the AI-based model [107, 108]. To this end, individual conditional expectation (ICE) [109] was first investigated to generate all possible partial responses. By design, ICE allows us to track any changes to the output response by varying a given input variable (other inputs remain unchanged). Consequently, ICE responses may be highly heterogeneous $[109,110]$. PD was then defined as the average of all partial responses. That way, PD reduces the complexity of the modeled relationship by 
graphing the significant relationship between the predicted output and the predictors. More details on the calculation of ICE and PD can be found in Goldstein et al. [109] and Molnar [111].

\section{Results and Discussion}

3.1. Training and Performance of ANFIS. This section presents the ANFIS training procedure. Before training, an initial Sugeno-type fuzzy inference system (FIS) was generated, as illustrated in Figure 4. The parameters of this initial FIS are also indicated in Table 3, showing the membership function type and the number of linear and nonlinear parameters. A hybrid combination of leastsquares and backpropagation gradient descent methods are used to optimize the initial FIS in accordance with the collection of input-output data. The cost function was the root mean square error, with 1000 being chosen as the stopping criterion. Figures 5(a) and 5(b) show the training process performance for one case in 11-cross folds in terms of cost function and step size, respectively, starting at a large value and decreasing to a smaller one. Figure 5(a) shows that convergence is obtained after about 600 iterations. An optimal step size profile of the ANFIS model initially increases, reaches a maximum, and then decreases for the rest of the training. Figures 6(a)-6(c) show the regression graphs using the training data, testing data, and all data, whereas Figures $7(\mathrm{a})-7(\mathrm{c})$ show both actual and predicted ultimate load as a function of sample index, respectively, for one case in 11-cross folds. Figures 6 and 7 show a strong correlation between the actual and predicted ultimate load. The average values of all quality assessment criteria at the end of the training process over 11 testing folds are given in Table 4 . The average values of $R^{2}$, RMSE, ErrorStD, and slope for training are $0.9861,89.93 \mathrm{kN}, 90.3333 \mathrm{kN}$, and 0.9861 , respectively. As indicated in Table $4, R^{2}=0.9637$, RMSE $=140.2420 \mathrm{kN}$, ErrorMean $=2.9249 \mathrm{kN}$, ErrorStD $=$ $141.9824 \mathrm{kN}$, and slope $=0.9806$, for the testing dataset. In addition, using all data, $R^{2}=0.9836$, RMSE $=97.8972 \mathrm{kN}$, ErrorMean $=0.2658 \mathrm{kN}, \quad$ ErrorStD $=98.2993 \mathrm{kN}, \quad$ and slope $=0.9859$. The overall responses confirm that the training process provides the optimal results. Finally, without exhibiting complex architecture, the proposed ANFIS model was able to produce the optimal results in an efficient way, avoiding costly computation.

3.2. Comparison with Literature. Various investigations have been introduced in the literature in order to predict the ultimate load of CFST members using AI-based approaches. A highlight of previous studies involving the reference, the model used, the cross section geometry, the number of data, the number of inputs, and quality assessment criteria is given in Table 5. Various AI methods have been employed, such as particle swarm optimization, support vector machine, gene expression programming, artificial neural network, and so on. In addition, the cross section may be circular or square. In terms of the value of quality assessment criteria, the ANFIS model improves the ultimate load prediction,

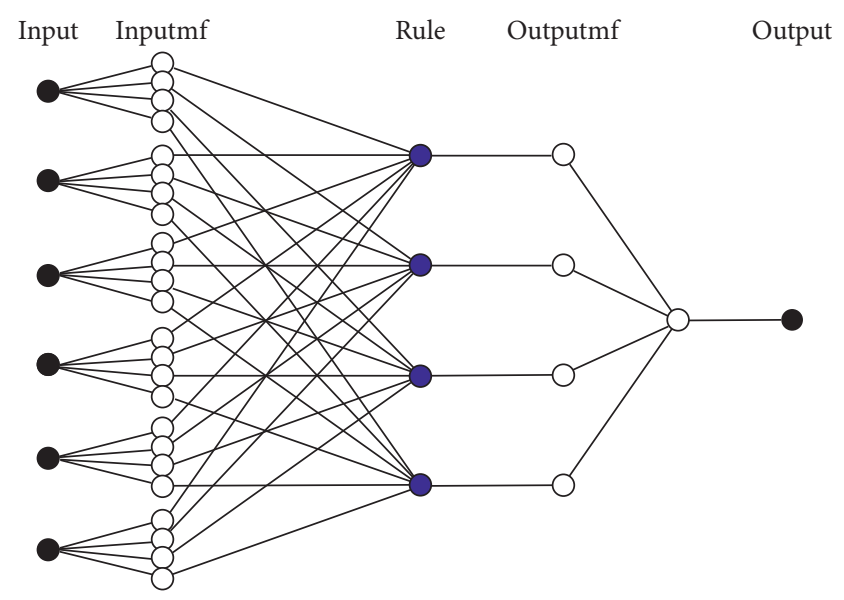

\begin{tabular}{c} 
Logical operations \\
AND \\
OR \\
\hline
\end{tabular}

FIgURE 4: ANFIS architecture used in this study. A colored circle indicates a fixed node, whereas an adaptive node is indicated by a white circle.

making it even more accurate than previously published results.

3.3. PD Analysis and Surface Mapping. Based on the validated ANFIS model developed previously, PD analysis is employed in this section to interpret the machine learning "black-box" model. Figures 8(a)-8(f) show the PD curve for $H, W, t, L, f_{y}$, and $f_{c}$, respectively. It should be noted that the best fit was also applied for each case. PD allows us to locally track the impact of each predictor on the output result. As an example, Figure 8(c) shows that the relationship between $N_{u}$ and $t$ can be approximated by a nonlinear quadratic equation such as $y=17.837 x^{2}+51.447 x+611.2$. That means the ultimate load of the columns increases when increasing the thickness of the steel tube following a nonlinear increment. The same conclusion (i.e., quadratic fit) was obtained for the cases of $H, W, f_{y}$, and $f_{c}^{\prime}$, but with different amplitudes (see Figures 8(a), 8(b), 8(e), and 8(f) for details of the equation). Besides, in the case of $L$, a third-order equation should be used to describe the relationship between $N_{u}$ and $L$. It is observed that the effect of $H, W, t, f_{y}$, and $f_{c}$ on $N_{u}$ is positive. However, Figure 8(d) shows that $L$ exhibits a negative effect on $N_{u}$. These observations were in accordance with the literature. If the length increases, the column becomes slender, and thus the ultimate load decreases. On the other hand, the ultimate load increases when increasing all other variables-especially the cross-sectional area (i.e., $H$, $W$, and $t)[21,35,36]$.

The PD analysis presented herein demonstrates that the machine learning technique can assist in the design of rectangular CFST members. In addition to a reliable prediction of ultimate load, as presented above, ANFIS can also assist in the creation of ultimate load maps, as illustrated in Figure 9. In particular, four input values are kept constant 
TABLE 3: Parameters of the ANFIS model.

Parameter

Value and description

Number of inputs

Number of outputs

Input membership function type

Number of parameters per membership function

Number of membership functions per input

Output membership function type

Number of nonlinear parameters

Number of linear parameters

Linear

Total number of parameters

Maximum iteration

28

Cost function-

Cost function

76
1000

Cross-validation

Root mean square error 11 folds

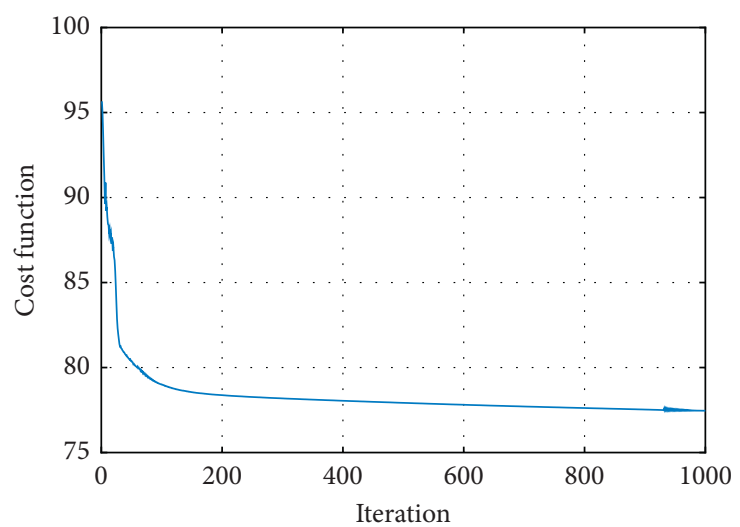

(a)

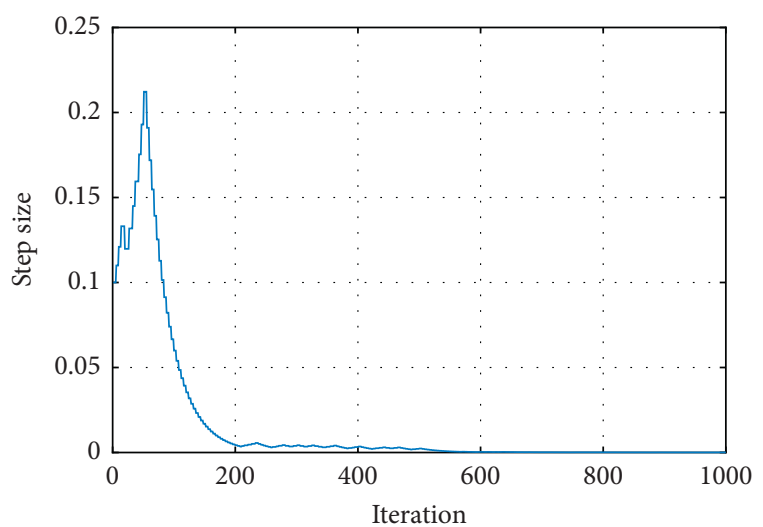

(b)

Figure 5: Cost functions: root mean square error (a) and step size (b), as a function of iteration.

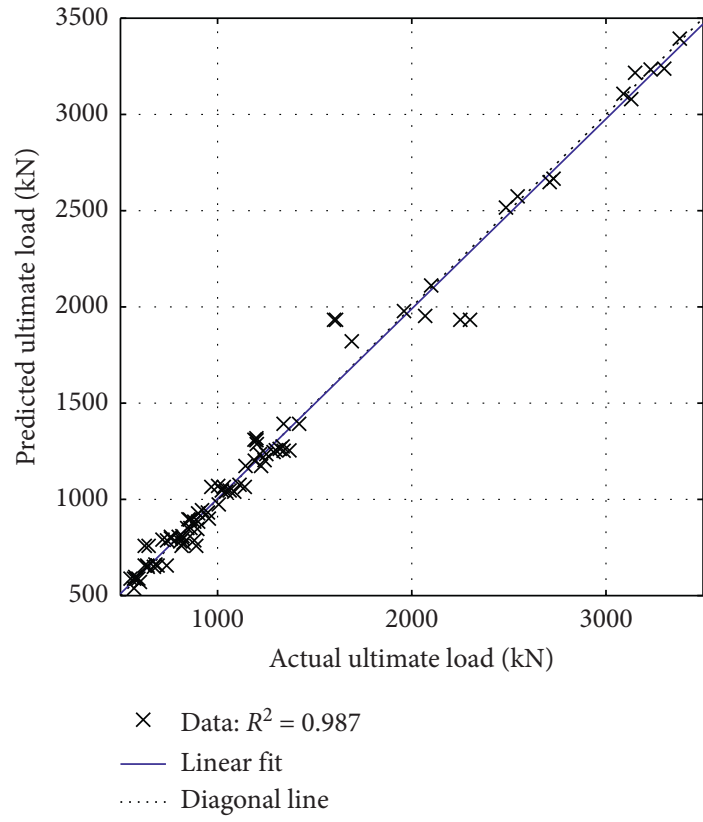

(a)

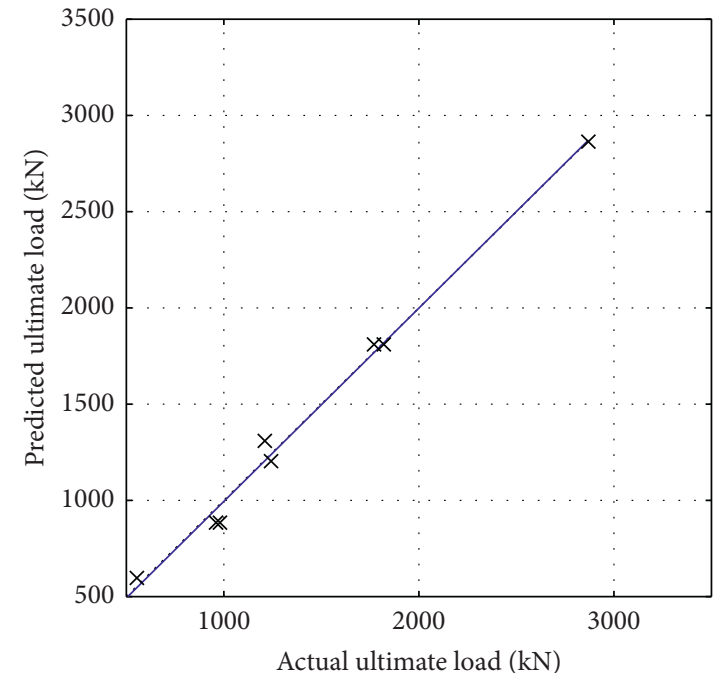

$\times \quad$ Data: $R^{2}=0.993$

— Linear fit

..... Diagonal line

FIgUre 6: Continued. 


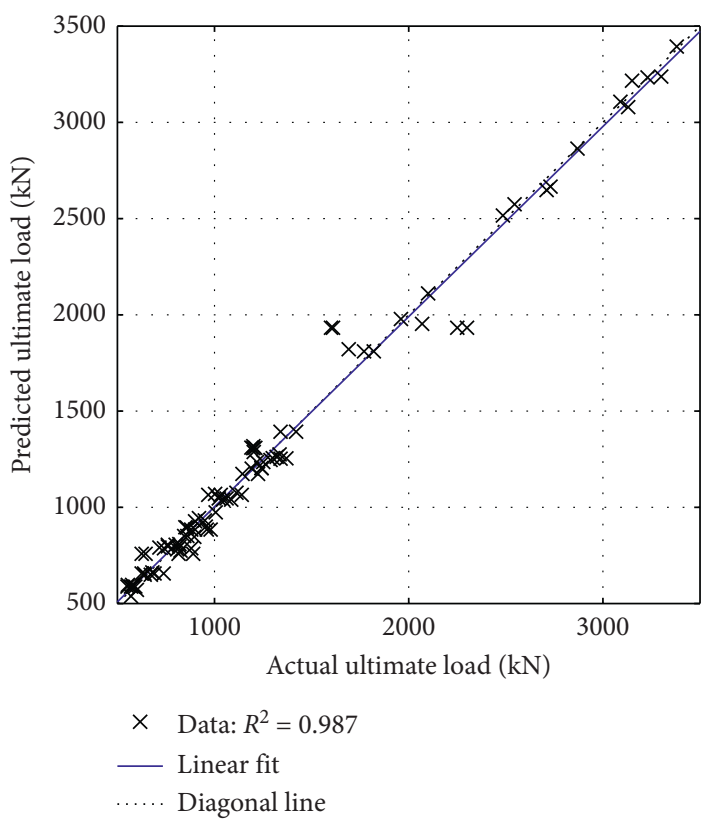

(c)

FIGURE 6: Regression between actual and predicted ultimate load: (a) using training data, (b) using testing data, and (c) using all data, for one case in 11-cross folds.

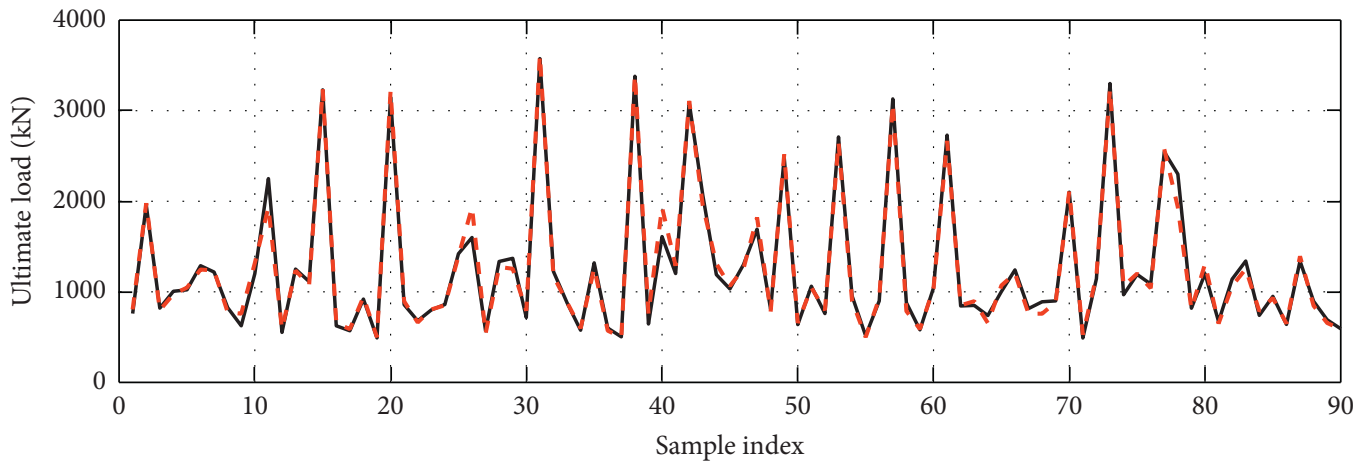

- Actual data

- - - Predicted data

(a)

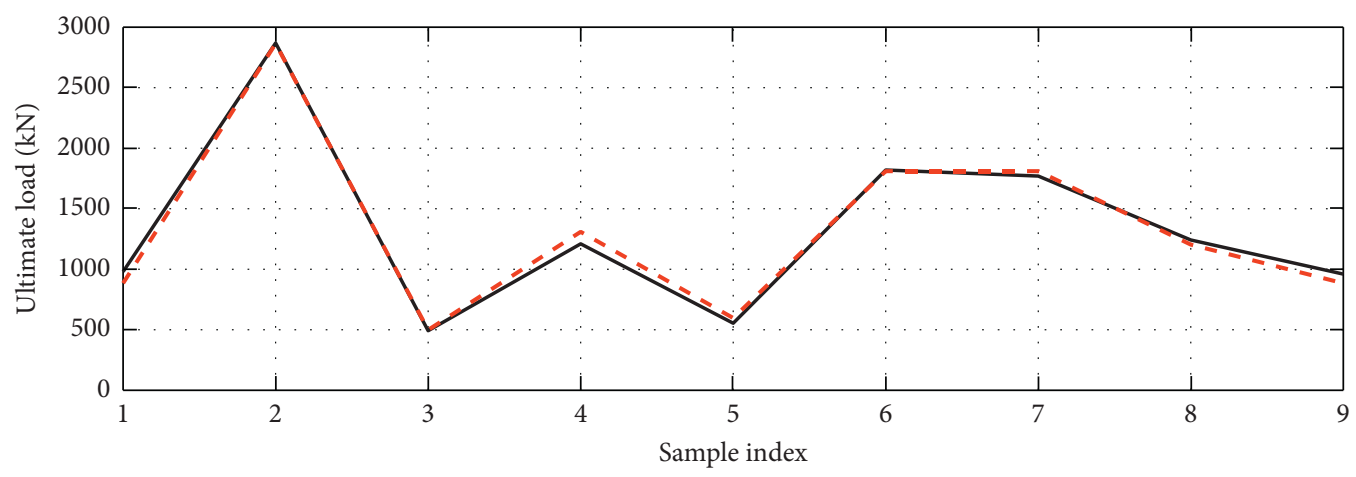

- Actual data

- _ - Predicted data

(b)

Figure 7: Continued. 


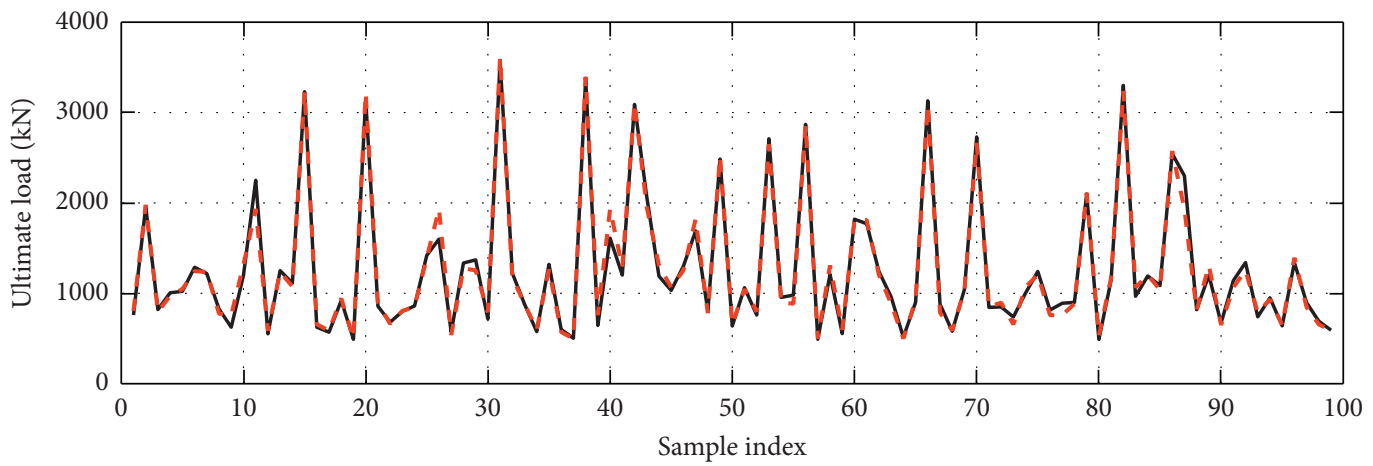

- Actual data

- - - Predicted data

(c)

FIGURE 7: Ultimate load as a function of sample index: (a) using training data, (b) using testing data, and (c) using all data, for one case in 11cross folds.

TABLE 4: Average prediction capability of ANFIS model over 11-cross folds.

\begin{tabular}{|c|c|c|c|c|c|}
\hline Data used & $R^{2}(-)$ & RMSE (kN) & ErrorMean $(\mathrm{kN})$ & ErrorStD $(\mathrm{kN})$ & Slope $(-)$ \\
\hline Training & 0.9861 & 89.8300 & -0.0001 & 90.3333 & 0.9861 \\
\hline Testing & 0.9637 & 140.2420 & 2.9249 & 141.9824 & 0.9806 \\
\hline All & 0.9836 & 97.8972 & 0.2658 & 98.2993 & 0.9859 \\
\hline
\end{tabular}

TABLE 5: Highlight of works for prediction of ultimate load of CFST members.

\begin{tabular}{|c|c|c|c|c|c|c|}
\hline Ref. & Model used & $\begin{array}{c}\text { Cross } \\
\text { section }\end{array}$ & $\begin{array}{l}\text { Number } \\
\text { of data }\end{array}$ & $\begin{array}{l}\text { Number } \\
\text { of inputs }\end{array}$ & Criteria used & Criteria values \\
\hline $\begin{array}{l}\text { Ren et al. } \\
{[35]}\end{array}$ & $\begin{array}{c}\text { Support vector } \\
\text { machine and particle } \\
\text { swarm optimization }\end{array}$ & Square & 180 & 7 & $\begin{array}{l}R^{2}, \text { MAPE, } \\
\text { MAE, MSE }\end{array}$ & $\begin{aligned} R^{2}=0.914, & \mathrm{MAPE}=0.145, \mathrm{MAE}=227 \mathrm{kN} \\
\mathrm{RMSE} & =304 \mathrm{kN}\end{aligned}$ \\
\hline $\begin{array}{l}\text { Tran et al. } \\
{[21]}\end{array}$ & $\begin{array}{l}\text { Artificial neural } \\
\text { network }\end{array}$ & Square & 300 & 5 & $R$ & $\begin{array}{c}R_{\text {training }}=0.99685, R_{\text {validating }}=0.99236, \\
R_{\text {testing }}=0.99366, R_{\text {all }}=0.99599\end{array}$ \\
\hline $\begin{array}{l}\text { Moon et al. } \\
{[61]}\end{array}$ & Fuzzy logic & Circular & 123 & 5 & $\begin{array}{l}\text { Average error, } \\
\text { standard } \\
\text { deviation }\end{array}$ & $\begin{array}{l}\text { Average error }=14.7,11.5 \text {, and } 11.2 \% \text {, } \\
\text { STD }=0.146,0.132, \text { and } 0.146\end{array}$ \\
\hline $\begin{array}{l}\text { Sarir et al. } \\
{[36]}\end{array}$ & $\begin{array}{l}\text { Gene expression } \\
\text { programming }\end{array}$ & Circular & 303 & 5 & $R^{2}$ & $R_{\text {training }}^{2}=0.928, R_{\text {testing }}^{2}=0.939$ \\
\hline $\begin{array}{l}\text { Ahmadi } \\
\text { et al. [57] }\end{array}$ & $\begin{array}{l}\text { Artificial neural } \\
\text { network }\end{array}$ & Circular & 268 & 5 & $R$ & $\begin{array}{c}R_{\text {training }}=0.93634, R_{\text {validating }}=0.93146 \\
R_{\text {testing }}=0.89924, R_{\text {all }}=0.92629\end{array}$ \\
\hline $\begin{array}{l}\text { Güneyisi } \\
\text { et al. [58] }\end{array}$ & $\begin{array}{l}\text { Gene expression } \\
\text { programming }\end{array}$ & Circular & 314 & 5 & $R$, MAPE, RMSE & $R=0.989, \mathrm{MAPE}=7.49, \mathrm{RMSE}=228 \mathrm{kN}$ \\
\hline This study & ANFIS & Rectangular & 99 & 6 & $\begin{array}{l}R^{2}, \mathrm{RMSE} \\
\text { ErrorMean, } \\
\text { ErrorStD, slope }\end{array}$ & $\begin{array}{c}R_{\text {training }}^{2}=0.9861, \mathrm{RMSE}_{\text {training }}=89.83 \mathrm{kN}, \\
\text { ErrorMean } \\
\text { Erraining }=0 \mathrm{kN}, \\
\text { slope }_{\text {training }}=0.986 \mathrm{R}_{\text {training }}^{2}=90.33 \mathrm{kN}, \\
\text { testing } \\
\text { testing } \\
=140.24 \mathrm{kN}, \\
\text { ErrorMean } \\
\text { testing } \\
=2.92 \mathrm{kN}, \\
\text { ErrorStD }_{\text {testing }}=141.98 \mathrm{kN}, \text { slope } \\
\text { testing }\end{array}$ \\
\hline
\end{tabular}

and a performance map is created, which depicts the influence of the other two input parameters on ultimate load. Thus, the proposed ANFIS model can create a huge number of maps, each time selecting the parameters that will be kept constant in order to examine the influence of the other two parameters on ultimate load.
In Figure 9, four maps of ultimate load are presented (same color range), involving the relationship between ultimate load and $t-L, t-W, t-f_{y}$, and $t-f_{c}$, respectively. Figure 9 (a) illustrates that a maximum value of ultimate load can be obtained if $t$ reaches its maximum and $L$ reaches its minimum value. On the other hand, the ultimate load 


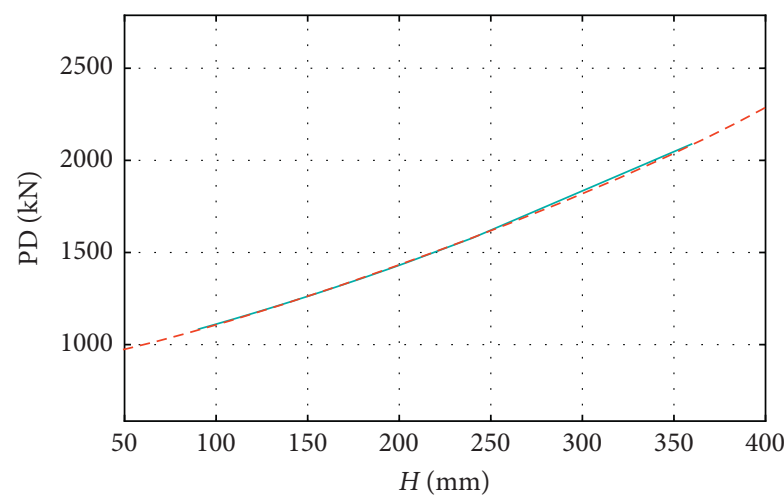

— PD vs. $H$

- - Quadratic fit: $y=0.0035 x^{2}+2.13 x+862.68$

(a)

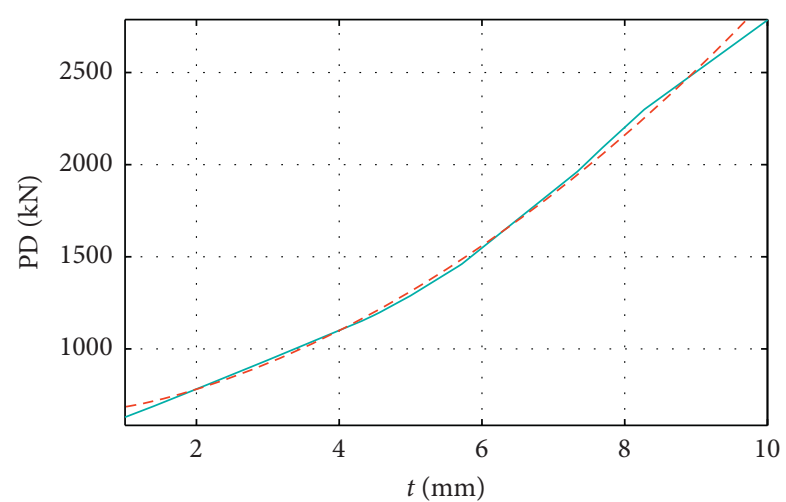

- PD vs. $t$

- - Quadratic fit: $y=17.837 x^{2}+51.447 x+611.2$

(c)

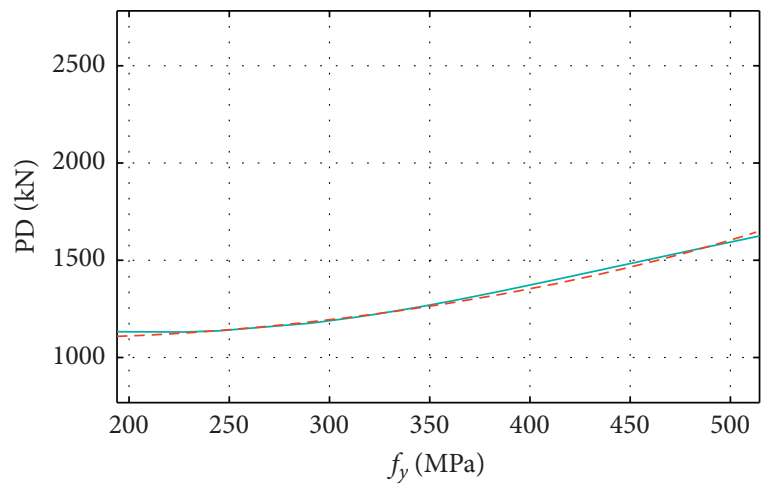

- PD vs. $f_{y}$

- - Q Quadratic fit: $y=0.0039 x^{2}-1.115 x+1181.8$

(e)

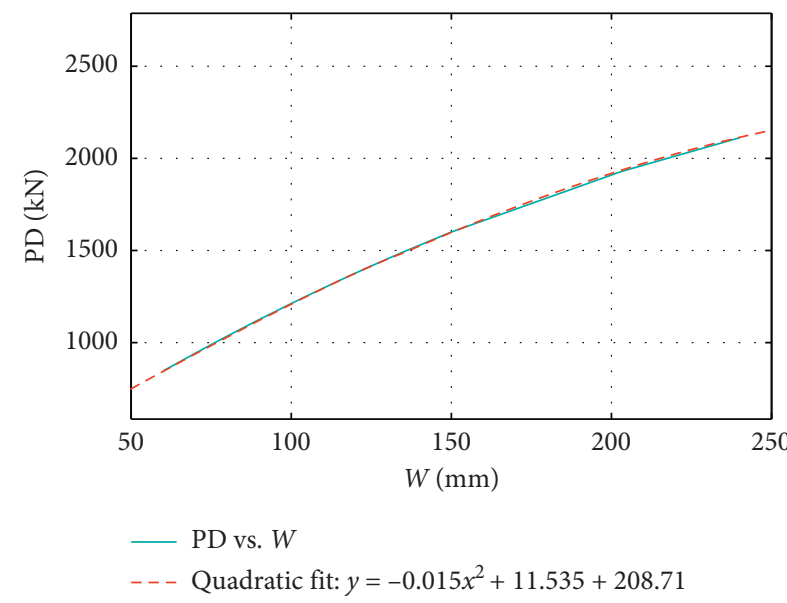

(b)

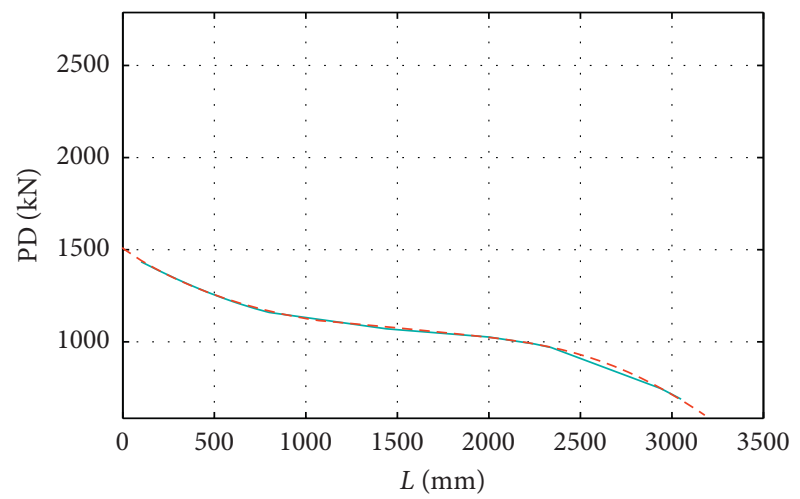

- PD vs. $L$

- - Cubic fit: $y=-8 e-8 x^{3}+0.00038 x^{2}-0.684 x$

$+1508.6$

(d)

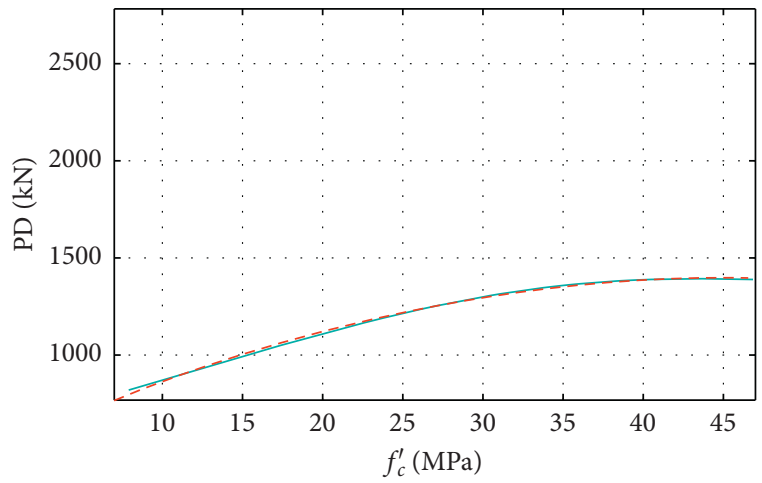

— PD vs. $f_{c}^{\prime}$

- - - Quadratic fit: $y=-0.415 x^{2}+37.998 x+526.1$

(f)

Figure 8: PD analysis for (a) $H$, (b) $W$, (c) $t$, (d) $L$, (e) $f_{y}$, and (f) $f_{c}$, respectively.

reaches its minimum if $L$ reaches its highest value and $t$ reaches its smallest value. This map confirms the negative effect of $L$ as identified by PD previously. In Figure 9(b), the ultimate load increases when increasing both $t$ and $W$ (i.e., increasing the cross-sectional area). The ultimate load is small when $t$ and $W$ are small. In Figures 9(c) and 9(d), the same remarks as in Figure 9(b) apply. However, the ultimate load may not reach the maximum values like the cases in Figures 9(a) and 9(b). This remark confirms that the geometric parameters of the cross section are more important 


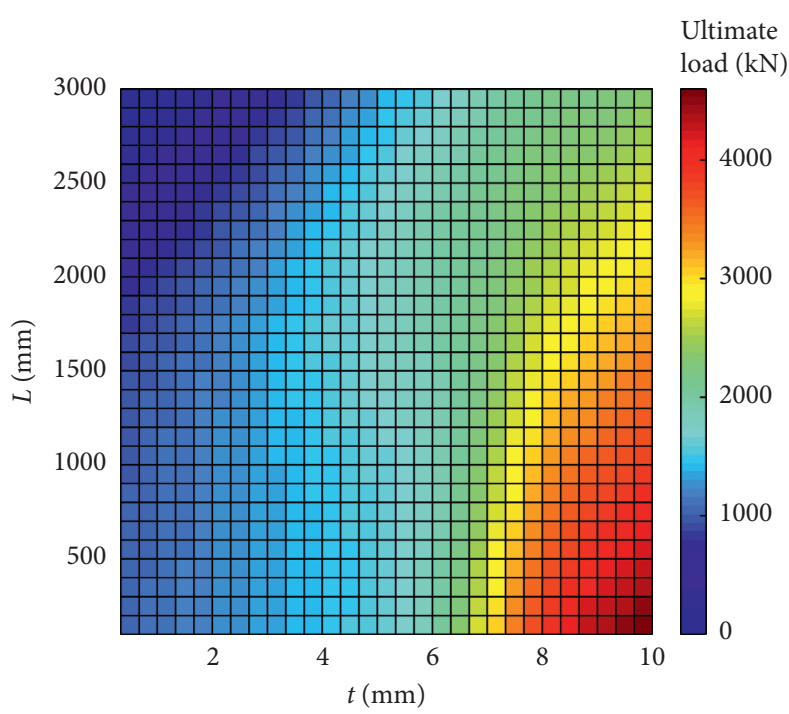

(a)

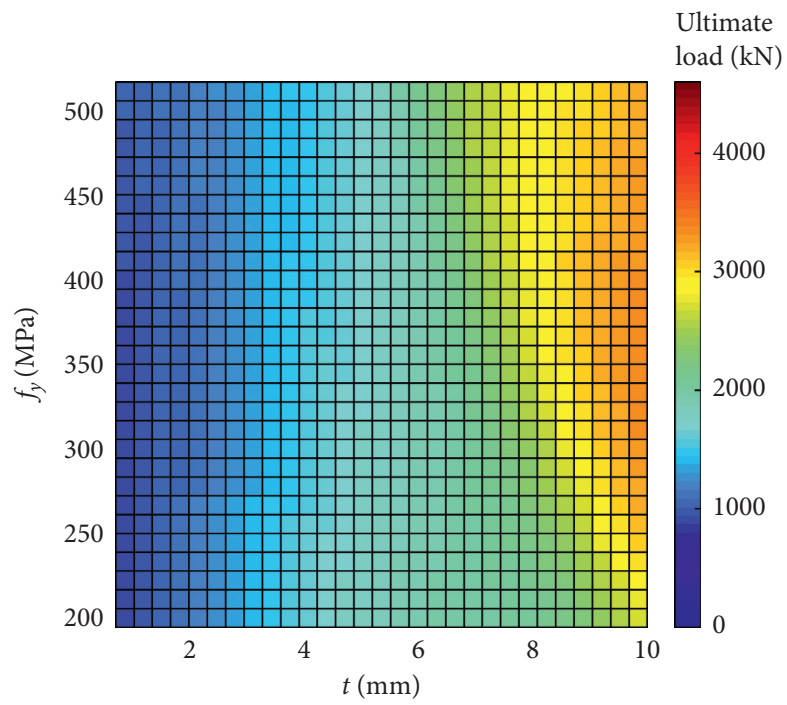

(c)

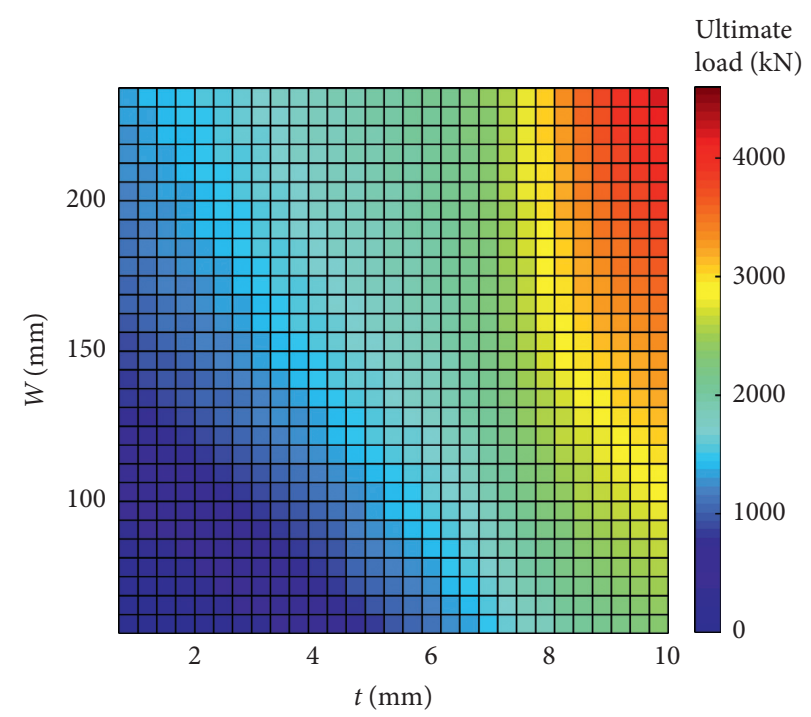

(b)

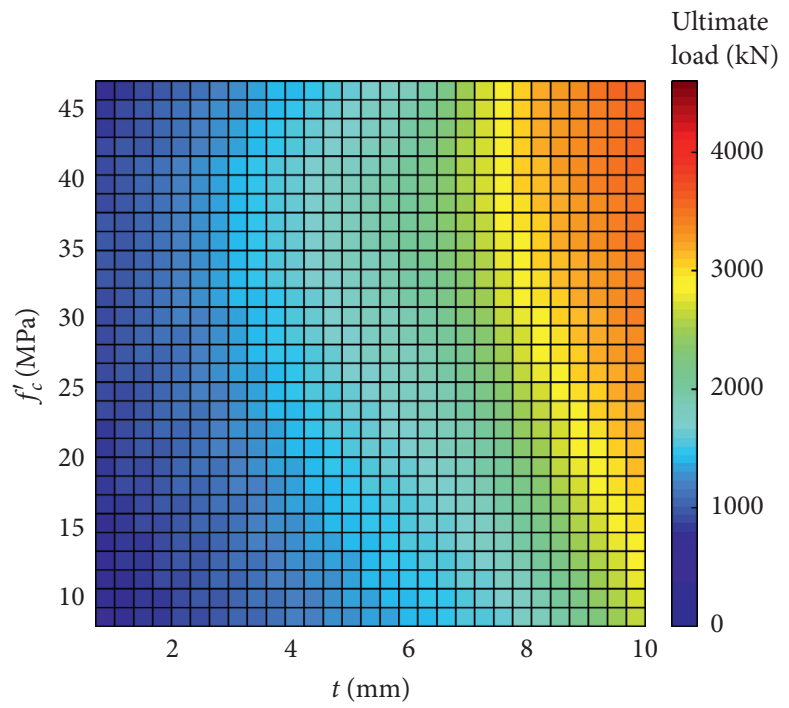

(d)

Figure 9: Maps of ultimate load as a function of (a) $t-L$, (b) $t-W$, (c) $t-f_{y}$, and (d) $t-f_{c}$.

than the mechanical properties of the constituent materials. Generally speaking, these observations are in close agreement with the experimental results in the literature $[21,35,36]$. The maps presented herein aim exclusively to demonstrate the advantage of the proposed machine learning approach. More datasets in a wider range are urgently required in order to deliver reliable maps, and this will be the salient goal for future work.
To quantify the level of influence (i.e., sensitivity rate) of each input variable, the integral of each $\mathrm{PD}$ curve was computed and served as an indicator of importance. Figure 10 plots the values of PD's area of six input variables as a bar graph (normalized to 1). The ANFIS model demonstrates that the geometric parameters of the cross section (i.e., $t, W$, and $H$ ) are the most important variables, followed by $L, f_{c}$, and $f_{y}$, respectively. Overall, without solving 


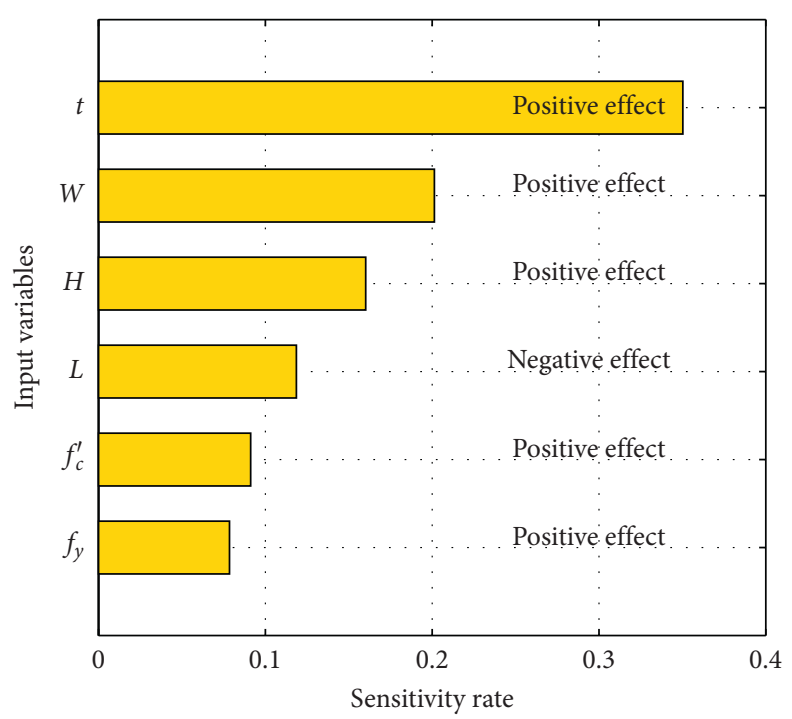

Figure 10: Sensitivity rate of each variable obtained from the ANFIS model.

complex mechanical equations, an interpretable ANFIS model could indicate nonlinear relationships efficiently, avoiding excessive computational cost.

\section{Conclusion and Outlook}

In this work, an ANFIS model was developed and trained to predict the ultimate load of rectangular CFST structural members under compression. Various statistical criteria such as coefficient of determination $\left(R^{2}\right)$, root mean square error (RMSE), and slope of linear regression were employed for error assessment. A hybrid combination of least-squares and backpropagation gradient descent method was used to train the ANFIS model. A 11-fold cross-validation technique was employed to evaluate the overall performance of the model. In comparison with the literature, the ANFIS exhibited excellent potential as a surrogate model for the prediction of the ultimate load of rectangular CFST columns. Moreover, the ANFIS model allowed us to quantitatively explore the influence of each input variable on the output response through $\mathrm{PD}$ analysis. In addition, many ultimate load maps were created using the ANFIS model. Such analysis could be useful in structural engineering design and evaluation. The developed ANFIS model could be useful in the predesign process, by exploring some initial calculations of the ultimate load before conducting any experimentation.

However, the application of an AI-based model is not always relevant for practical engineering. In further studies, an explicit empirical equation based on the ANFIS model developed here should be derived for better use in design and analysis. In addition, a numerical finite element scheme should be investigated for studying the mechanical behaviors of composite structures at both micro and macro scales. The finite element scheme could also be coupled with AI approaches to shed further light on the relationship between the micro and macro behaviors of CFST members. In future research, a broader database should be used, in order to cover more material properties and geometric ranges.
Finally, the methodology used in this work could be extended to estimate macroscopic properties of CFST members under different loads and boundary conditions (bending, eccentric compression, beam-column joint, etc.).

\section{Data Availability}

The Excel data used to support the findings of this study are available from the corresponding author upon request.

\section{Conflicts of Interest}

The authors declare that there are no conflicts of interest.

\section{References}

[1] F.-X. Ding, C. Fang, Y. Bai, and Y.-Z. Gong, "Mechanical performance of stirrup-confined concrete-filled steel tubular stub columns under axial loading," Journal of Constructional Steel Research, vol. 98, pp. 146-157, 2014.

[2] L.-H. Han and G.-H. Yao, "Influence of concrete compaction on the strength of concrete-filled steel RHS columns," Journal of Constructional Steel Research, vol. 59, no. 6, pp. 751-767, 2003.

[3] M. H. Lai and J. C. M. Ho, "Effect of continuous spirals on uni-axial strength and ductility of CFST columns," Journal of Constructional Steel Research, vol. 104, pp. 235-249, 2015.

[4] K. M. A. Hossain and K. Chu, "Confinement of six different concretes in CFST columns having different shapes and slenderness," International Journal of Advanced Structural Engineering, vol. 11, no. 2, pp. 255-270, 2019.

[5] L.-H. Han and Y.-F. An, "Performance of concrete-encased CFST stub columns under axial compression," Journal of Constructional Steel Research, vol. 93, pp. 62-76, 2014.

[6] Y.-L. Shi, W. Xian, W.-D. Wang, and H.-W. Li, "Mechanical behaviour of circular steel-reinforced concrete-filled steel tubular members under pure bending loads," Structures, vol. 25, pp. 8-23, 2020.

[7] F. Ali, A. Nadjai, and N. Goodfellow, "Experimental and numerical study on the performance of hollow and concrete- 
filled elliptical steel columns subjected to severe fire," Fire and Materials, vol. 40, no. 4, pp. 635-652, 2016.

[8] A. Espinos, L. Gardner, M. L. Romero, and A. Hospitaler, "Fire behaviour of concrete filled elliptical steel columns," Thin-Walled Structures, vol. 49, no. 2, pp. 239-255, 2011.

[9] A. Masi, G. Santarsiero, A. Mossucca, and D. Nigro, "Influence of axial load on the seismic behavior of RC beamcolumn joints with wide beam," Applied Mechanics and Materials, vol. 508, pp. 208-214, 2014.

[10] D.-Y. Ma, L.-H. Han, and X.-L. Zhao, "Seismic performance of the concrete-encased CFST column to RC beam joint: experiment," Journal of Constructional Steel Research, vol. 154, pp. 134-148, 2019.

[11] R. Yadav, B. Chen, H. Yuan, and Z. Lian, "Experimental investigation of CFST-RC bridge piers under cyclic loading," Procedia Engineering, vol. 173, pp. 1723-1730, 2017.

[12] V. Q. Tran, H. L. Nguyen, V. D. Dao et al., "Temperature effects on chloride binding capacity of cementitious materials," Magazine of Concrete Research, pp. 1-39, 2019, In press.

[13] X. Qu, Z. Chen, and G. Sun, "Experimental study of rectangulars CFST columns subjected to eccentric loading," Thin-Walled Structures, vol. 64, pp. 83-93, 2013.

[14] M. H. Mahmoud, H. M. Afefy, N. M. Kassem, and T. M. Fawzy, "Strengthening of defected beam-column joints using CFRP," Journal of Advanced Research, vol. 5, no. 1, pp. $67-77,2014$

[15] L.-H. Han, W. Li, and R. Bjorhovde, "Developments and advanced applications of concrete-filled steel tubular (CFST) structures: members," Journal of Constructional Steel Research, vol. 100, pp. 211-228, 2014.

[16] A. Zhu, X. Zhang, H. Zhu, J. Zhu, and Y. Lu, "Experimental study of concrete filled cold-formed steel tubular stub columns," Journal of Constructional Steel Research, vol. 134, pp. 17-27, 2017.

[17] T.-M. Chan, Y.-M. Huai, and W. Wang, "Experimental investigation on lightweight concrete-filled cold-formed elliptical hollow section stub columns," Journal of Constructional Steel Research, vol. 115, pp. 434-444, 2015.

[18] Eurocode 4, Design of Composite Steel and Concrete Structures. Part 1.1, General Rules and Rules for Buildings, European Committee for Standardization, British Standards Institution, London, UK, 2004.

[19] American Institute of Steel Construction, Specification for Structural Steel Buildings, American Institute of Steel Construction, Chicago, IL, USA, 2010.

[20] ACI Committee, 318-08: Building Code Requirements for Structural Concrete and Commentary, American Concrete Institute, Farmington Hills, MI, USA, 2011.

[21] V.-L. Tran, D.-K. Thai, and S.-E. Kim, "Application of ANN in predicting ACC of SCFST column," Composite Structures, vol. 228, p. 111332, 2019.

[22] M.-X. Xiong, D.-X. Xiong, and J. Y. R. Liew, "Axial performance of short concrete filled steel tubes with high- and ultra-high- strength materials," Engineering Structures, vol. 136, pp. 494-510, 2017.

[23] Z.-B. Wang, Z. Tao, L.-H. Han, B. Uy, D. Lam, and W.-H. Kang, "Strength, stiffness and ductility of concretefilled steel columns under axial compression," Engineering Structures, vol. 135, pp. 209-221, 2017.

[24] A. Kuranovas, D. Goode, A. K. Kvedaras, and S. Zhong, "Load-bearing capacity of concrete-filled steel columns," Journal of Civil Engineering and Management, vol. 15, no. 1, pp. 21-33, 2009.
[25] L.-H. Han, C. Hou, and Q.-L. Wang, "Square concrete filled steel tubular (CFST) members under loading and chloride corrosion: experiments," Journal of Constructional Steel Research, vol. 71, pp. 11-25, 2012.

[26] L. He, Y. Zhao, and S. Lin, "Experimental study on axially compressed circular CFST columns with improved confinement effect," Journal of Constructional Steel Research, vol. 140, pp. 74-81, 2018.

[27] Y.-F. An and L.-H. Han, "Behaviour of concrete-encased CFST columns under combined compression and bending," Journal of Constructional Steel Research, vol. 101, pp. 314-330, 2014.

[28] K. Zhou and L.-H. Han, "Modelling the behaviour of concrete-encased concrete-filled steel tube (CFST) columns subjected to full-range fire," Engineering Structures, vol. 183, pp. 265-280, 2019.

[29] D. H. Nguyen, W.-K. Hong, H.-J. Ko, and S.-K. Kim, "Finite element model for the interface between steel and concrete of CFST (concrete-filled steel tube)," Engineering Structures, vol. 185, pp. 141-158, 2019.

[30] P. K. Gupta, A. K. Ahuja, and Z. A. Khaudhair, "Modelling, verification and investigation of behaviour of circular CFST columns," Structural Concrete, vol. 15, no. 3, pp. 340-349, 2014.

[31] Y.-F. Yang and C. Hou, "Performance of partially compressed CFST columns through dissimilarly shaped bearing plates under axial load," Thin-Walled Structures, vol. 120, pp. 333-354, 2017.

[32] F.-Y. Liao, L.-H. Han, and Z. Tao, "Behaviour of CFST stub columns with initial concrete imperfection: analysis and calculations," Thin-Walled Structures, vol. 70, pp. 57-69, 2013.

[33] Z.-L. Du, Y.-P. Liu, J.-W. He, and S.-L. Chan, "Direct analysis method for noncompact and slender concrete-filled steel tube members," Thin-Walled Structures, vol. 135, pp. 173184,2019

[34] L.-H. Han, G.-H. Yao, and X.-L. Zhao, "Tests and calculations for hollow structural steel (HSS) stub columns filled with self-consolidating concrete (SCC)," Journal of Constructional Steel Research, vol. 61, no. 9, pp. 1241-1269, 2005.

[35] Q. Ren, M. Li, M. Zhang, Y. Shen, and W. Si, "Prediction of ultimate axial capacity of square concrete-filled steel tubular short columns using a hybrid intelligent algorithm," Applied Sciences, vol. 9, no. 14, p. 2802, 2019.

[36] P. Sarir, J. Chen, P. G. Asteris, D. J. Armaghani, and M. M. Tahir, "Developing GEP tree-based, neuro-swarm, and whale optimization models for evaluation of bearing capacity of concrete-filled steel tube columns," Engineering with Computers, 2019, In press.

[37] B. Murali Krishna, V. Guru Prathap Reddy, M. Shafee, and T. Tadepalli, "Condition assessment of RC beams using artificial neural networks," Structures, vol. 23, pp. 1-12, 2020.

[38] H.-B. Ly, B. T. Pham, L. M. Le, T.-T. Le, V. M. Le, and P. G. Asteris, "Estimation of axial load-carrying capacity of concrete-filled steel tubes using surrogate models," Neural Computing and Applications, 2020, In press.

[39] T.-T. Le, "Surrogate neural network model for prediction of load-bearing capacity of CFSS members considering loading eccentricity," Applied Sciences, vol. 10, no. 10, p. 3452, 2020.

[40] H. Thanh Duong, H. Chi Phan, T.-T. Le, and N. Duc Bui, "Optimization design of rectangular concrete-filled steel tube short columns with Balancing Composite Motion Optimization and data-driven model," Structures, vol. 28, pp. 757-765, 2020. 
[41] T.-T. Le, "Practical hybrid machine learning approach for estimation of ultimate load of elliptical concrete-filled steel tubular columns under axial loading," Advances in Civil Engineering, vol. 2020, Article ID 8832522, 19 pages, 2020.

[42] T.-T. Le, "Practical machine learning-based prediction model for axial capacity of square CFST columns," Mechanics of Advanced Materials and Structures, pp. 1-16, 2020, In press.

[43] T.-T. Le, "Prediction of tensile strength of polymer carbon nanotube composites using practical machine learning method," Journal of Composite Materials, 2020, In press.

[44] V.-L. Tran, D.-K. Thai, and D.-D. Nguyen, "Practical artificial neural network tool for predicting the axial compression capacity of circular concrete-filled steel tube columns with ultra-high-strength concrete," Thin-Walled Structures, vol. 151, Article ID 106720, 2020.

[45] V.-L. Tran and S.-E. Kim, "Efficiency of three advanced datadriven models for predicting axial compression capacity of CFDST columns," Thin-Walled Structures, vol. 152, Article ID 106744, 2020.

[46] V.-L. Tran, D.-K. Thai, and S.-E. Kim, "A new empirical formula for prediction of the axial compression capacity of CCFT columns," Steel and Composite Structures, vol. 33, pp. 181-194, 2019.

[47] H.-B. Ly, L. M. Le, H. T. Duong et al., "Hybrid artificial intelligence approaches for predicting critical buckling load of structural members under compression considering the influence of initial geometric imperfections," Applied Sciences, vol. 9, no. 11, p. 2258, 2019.

[48] L. M. Le, H.-B. Ly, B. T. Pham et al., "Hybrid artificial intelligence approaches for predicting buckling damage of steel columns under axial compression," Materials, vol. 12, no. 10, p. $1670,2019$.

[49] E. M. A. El-Kassas, R. I. Mackie, and A. I. El-Sheikh, "Using neural networks to predict the design load of cold-formed steel compression members," Advances in Engineering Software, vol. 33, no. 7-10, pp. 713-719, 2002.

[50] H.-B. Ly, T.-T. Le, L. M. Le et al., "Development of hybrid machine learning models for predicting the critical buckling load of I-shaped cellular beams," Applied Sciences, vol. 9, no. 24, p. 5458, 2019.

[51] H.-B. Ly, B. T. Pham, D. V. Dao, V. M. Le, L. M. Le, and T.-T. Le, "Improvement of ANFIS model for prediction of compressive strength of manufactured sand concrete," Applied Sciences, vol. 9, no. 18, p. 3841, 2019.

[52] D. Dao, S. Trinh, H.-B. Ly, and B. Pham, "Prediction of compressive strength of geopolymer concrete using entirely steel slag aggregates: novel hybrid artificial intelligence approaches," Applied Sciences, vol. 9, no. 6, p. 1113, 2019.

[53] P. G. Asteris, A. Ashrafian, and M. Rezaie-Balf, "Prediction of the compressive strength of self-compacting concrete using surrogate models," Computers and Concrete, vol. 24, no. 2, pp. 137-150, 2019.

[54] P. G. Asteris and K. G. Kolovos, "Self-compacting concrete strength prediction using surrogate models," Neural Computing and Applications, vol. 31, no. 1, pp. 409-424, 2019.

[55] D. V. Dao, H. Adeli, H.-B. Ly et al., "A sensitivity and robustness analysis of GPR and ANN for high-performance concrete compressive strength prediction using a Monte Carlo simulation," Sustainability, vol. 12, no. 3, p. 830, 2020.

[56] M. Ahmadi, H. Naderpour, and A. Kheyroddin, "Utilization of artificial neural networks to prediction of the capacity of CCFT short columns subject to short term axial load,"
Archives of Civil and Mechanical Engineering, vol. 14, no. 3, pp. 510-517, 2014.

[57] M. Ahmadi, H. Naderpour, and A. Kheyroddin, "ANN model for predicting the compressive strength of circular steel-confined concrete," International Journal of Civil Engineering, vol. 15, no. 2, pp. 213-221, 2017.

[58] E. M. Güneyisi, A. Gültekin, and K. Mermerdaş, "Ultimate capacity prediction of axially loaded CFST short columns," International Journal of Steel Structures, vol. 16, no. 1, pp. 99-114, 2016.

[59] S. İpek and E. M. Güneyisi, "Ultimate axial strength of concrete-filled double skin steel tubular column sections," Advances in Civil Engineering, vol. 2019, Article ID 6493037, 19 pages, 2019.

[60] A. M. Al-Khaleefi, M. J. Terro, A. P. Alex, and Y. Wang, "Prediction of fire resistance of concrete filled tubular steel columns using neural networks," Fire Safety Journal, vol. 37, no. 4, pp. 339-352, 2002.

[61] J. Moon, J. J. Kim, T.-H. Lee, and H.-E. Lee, "Prediction of axial load capacity of stub circular concrete-filled steel tube using fuzzy logic," Journal of Constructional Steel Research, vol. 101, pp. 184-191, 2014.

[62] S. P. Schneider, "Axially loaded concrete-filled steel tubes," Journal of Structural Engineering, vol. 124, no. 10, pp. 1125-1138, 1998.

[63] Y. Du, Z. Chen, and M.-X. Xiong, "Experimental behavior and design method of rectangular concrete-filled tubular columns using Q460 high-strength steel," Construction and Building Materials, vol. 125, pp. 856-872, 2016

[64] S. Ghannam, Y. A. Jawad, and Y. Hunaiti, "Failure of lightweight aggregate concrete-filled steel tubular columns," Steel and Composite Structures, vol. 4, no. 1, pp. 1-8, 2004.

[65] R. Q. Bridge, Concrete Filled Steel Tubular Columns.School of Civil Engineering, University of Sydney, Sydney, Australia, 1976, https://trove.nla.gov.au/work/35477622?q\&versionId=44129332.

[66] Y. Du, Z. Chen, and Y. Yu, "Behavior of rectangular concrete-filled high-strength steel tubular columns with different aspect ratio," Thin-Walled Structures, vol. 109, pp. 304-318, 2016.

[67] L.-H. Han, "Tests on stub columns of concrete-filled RHS sections," Journal of Constructional Steel Research, vol. 58, no. 3, pp. 353-372, 2002.

[68] L.-H. Han and Y.-F. Yang, "Analysis of thin-walled steel RHS columns filled with concrete under long-term sustained loads," Thin-Walled Structures, vol. 41, no. 9, pp. 849-870, 2003.

[69] C. Y. Lin, "Axial capacity of concrete infilled cold-formed steel columns," in Proceedings of the Ninth International Specialty Conference on Cold-Formed Steel Structures, pp. 443-457, St. Louis, MO, USA, November 1988.

[70] S. P. Schneider, "Axially loaded concrete-filled steel tubes," Journal of Structural Engineering, vol. 124, no. 10, pp. 1125-1138, 1998.

[71] H. Shakir-Khalil and M. Mouli, "Further tests on concretefilled rectangular hollow-section columns," The Structural Engineer, vol. 68, pp. 405-413, 1990.

[72] H. Shakir-Khalil and J. Zeghiche, "Experimental behaviour of concrete-filled rolled rectangular hollow-section columns," The Structural Engineer, vol. 67, pp. 346-353, 1989.

[73] H. Takagi and M. Sugeno, "Derivation of fuzzy control rules from human operator's control actions," in Proceedings of the IFAC Symposium on Fuzzy Information, Knowledge Representation and Decision Analysis, pp. 55-60, Marseille, France, July 1983. 
[74] P. Werbos, "Beyond regression: new tools for prediction and analysis in the behavioral sciences," Ph.D. Thesis, Harvard University, Cambridge, MA, USA, 1974.

[75] J.-S. R. Jang, "ANFIS adaptive-network-based fuzzy inference system," IEEE Transactions on Systems Man and Cybernetics, vol. 23, no. 3, pp. 665-685, 1993.

[76] A. Sadrmomtazi, J. Sobhani, and M. A. Mirgozar, "Modeling compressive strength of EPS lightweight concrete using regression, neural network and ANFIS," Construction and Building Materials, vol. 42, pp. 205-216, 2013.

[77] J. Gill and J. Singh, "Adaptive neuro-fuzzy inference system approach to predict the mass flow rate of R-134a/LPG refrigerant for straight and helical coiled adiabatic capillary tubes in the vapor compression refrigeration system," International Journal of Refrigeration, vol. 78, pp. 166-175, 2017.

[78] H.-A. Pham, V.-H. Truong, and M.-T. Tran, "Fuzzy static finite element analysis for functionally graded structures with semi-rigid connections," Structures, vol. 26, pp. 639650, 2020.

[79] M. Aditya, C. Chatterjee, and R. N. Singh, "Flood forecasting using ANN, neuro-fuzzy, and neuro-GA models," Journal of Hydrologic Engineering, vol. 14, pp. 647-652, 2009.

[80] P. C. Nayak, K. P. Sudheer, D. M. Rangan, and K. S. Ramasastri, "Short-term flood forecasting with a neurofuzzy model," Water Resources Research, vol. 41, no. 4, pp. 1-16, 2005.

[81] S. Akbulut, A. S. Hasiloglu, and S. Pamukcu, "Data generation for shear modulus and damping ratio in reinforced sands using adaptive neuro-fuzzy inference system," Soil Dynamics and Earthquake Engineering, vol. 24, no. 11, pp. 805-814, 2004.

[82] E. T. Fonseca, P. C. G. d. S. Vellasco, M. M. B. R. Vellasco, and S. A. L. de Andrade, "A neuro-fuzzy evaluation of steel beams patch load behaviour," Advances in Engineering Software, vol. 39, no. 7, pp. 558-572, 2008.

[83] S. Tesfamariam and H. Najjaran, "Adaptive network-fuzzy inferencing to estimate concrete strength using mix design," Journal of Materials in Civil Engineering, vol. 19, no. 7, pp. 550-560, 2007.

[84] G. Hu, H. Phan, R. Ouache, H. Gandhi, K. Hewage, and R. Sadiq, "Fuzzy fault tree analysis of hydraulic fracturing flowback water storage failure," Journal of Natural Gas Science and Engineering, vol. 72, p. 103039, 2019.

[85] H.-A. Pham, V.-H. Truong, and T.-C. Vu, "Fuzzy finite element analysis for free vibration response of functionally graded semi-rigid frame structures," Applied Mathematical Modelling, vol. 88, pp. 852-869, 2020.

[86] K.-T. T. Bui, D. T. Bui, J. Zou, C. V. Doan, and I. Revhaug, "A novel hybrid artificial intelligent approach based on neural fuzzy inference model and particle swarm optimization for horizontal displacement modeling of hydropower dam," Neural Computing and Application, vol. 27, no. 8, pp. 1495-1506, 2016.

[87] W. Yong, J. Zhou, D. Jahed Armaghani et al., "A new hybrid simulated annealing-based genetic programming technique to predict the ultimate bearing capacity of piles," Engineering with Computers, 2020.

[88] M. Koopialipoor, B. R. Murlidhar, A. Hedayat, D. J. Armaghani, B. Gordan, and E. T. Mohamad, "The use of new intelligent techniques in designing retaining walls," Engineering with Computers, vol. 36, no. 1, pp. 283-294, 2020.
[89] B. T. Pham, L. M. Le, T.-T. Le et al., "Development of advanced artificial intelligence models for daily rainfall prediction," Atmospheric Research, vol. 237, p. 104845, 2020.

[90] M. F. Badawy, M. A. Msekh, K. M. Hamdia, M. K. Steiner, T. Lahmer, and T. Rabczuk, "Hybrid nonlinear surrogate models for fracture behavior of polymeric nanocomposites," Probabilistic Engineering Mechanics, vol. 50, pp. 64-75, 2017.

[91] J.-S. Chou and A.-D. Pham, "Enhanced artificial intelligence for ensemble approach to predicting high performance concrete compressive strength," Construction and Building Materials, vol. 49, pp. 554-563, 2013.

[92] D.-K. Bui, T. Nguyen, J.-S. Chou, H. Nguyen-Xuan, and T. D. Ngo, "A modified firefly algorithm-artificial neural network expert system for predicting compressive and tensile strength of high-performance concrete," Construction and Building Materials, vol. 180, pp. 320-333, 2018.

[93] J. Guilleminot, T. T. Le, and C. Soize, "Stochastic framework for modeling the linear apparent behavior of complex materials: application to random porous materials with interphases," Acta Mechanica Sinica, vol. 29, no. 6, pp. 773-782, 2013.

[94] C. Soize, C. Desceliers, J. Guilleminot et al., "Stochastic representations and statistical inverse identification for uncertainty quantification in computational mechanics," in Proceedings of the UNCECOMP 2015, 1st ECCOMAS Thematic International Conference on Uncertainty Quantification in Computational Sciences and Engineering, pp. 1-26, Crete, Greece, May 2015.

[95] T. X. Nguyen, L. M. Le, T. C. Nguyen et al., "Characterization of soybeans and calibration of their DEM input parameters," Particulate Science and Technology, 2020.

[96] Q. H. Nguyen, H.-B. Ly, V. Q. Tran et al., "A novel hybrid model based on a feedforward neural network and one step secant algorithm for prediction of load-bearing capacity of rectangular concrete-filled steel tube columns," Molecules, vol. 25 , no. 15 , p. $3486,2020$.

[97] T.-T. Le, "Probabilistic investigation of the effect of stochastic imperfect interfaces in nanocomposites," Mechanics of Materials, vol. 151, Article ID 103608, 2020.

[98] H. Q. Nguyen, H.-B. Ly, V. Q. Tran, T.-A. Nguyen, T.-T. Le, and B. T. Pham, "Optimization of artificial intelligence system by evolutionary algorithm for prediction of axial capacity of rectangular concrete filled steel tubes under compression," Materials, vol. 13, no. 5, p. 1205, 2020.

[99] Q. H. Nguyen, H.-B. Ly, T.-T. Le et al., "Parametric investigation of particle swarm optimization to improve the performance of the adaptive neuro-fuzzy inference system in determining the buckling capacity of circular opening steel beams," Materials, vol. 13, no. 10, p. 2210, 2020.

[100] H.-B. Ly, T.-T. Le, H.-L. T. Vu, V. Q. Tran, L. M. Le, and B. T. Pham, "Computational hybrid machine learning based prediction of shear capacity for steel fiber reinforced concrete beams," Sustainability, vol. 12, no. 7, p. 2709, 2020.

[101] B. T. Pham, T. Nguyen-Thoi, H.-B. Ly et al., "Extreme learning machine based prediction of soil shear strength: a sensitivity analysis using Monte Carlo simulations and feature backward elimination," Sustainability, vol. 12, no. 6, p. $2339,2020$.

[102] T.-T. Le, Modélisation stochastique, en mécanique des milieux continus, de l'interphase inclusion-matrice à partir de simulations en dynamique moléculaire, Ph.D. Thesis, University of Paris-Est Marne-la-Vallée, Champs-sur-Marne, France, 2020, http://www.theses.fr/2015PESC1172. 
[103] H. C. Phan, A. S. Dhar, G. Hu, and R. Sadiq, "Managing water main breaks in distribution networks--A risk-based decision making," Reliability Engineering \& System Safety, vol. 191, Article ID 106581, 2019.

[104] H. C. Phan, A. S. Dhar, P. Thodi, and R. Sadiq, "Probability of network disconnection of water distribution system for maintenance prioritization," Journal of Water Supply: Research and Technology-Aqua, vol. 67, no. 3, pp. 252-269, 2018.

[105] T.-T. Le, "Multiscale analysis of elastic properties of nanoreinforced materials exhibiting surface effects. application for determination of effective shear modulus," Journal of Composites Science, vol. 4, no. 4, p. 172, 2020.

[106] T.-T. Le, "Probabilistic modeling of surface effects in nanoreinforced materials," Computational Materials Science, vol. 186, p. 109987, 2021.

[107] C. Qi, X. Tang, X. Dong, Q. Chen, A. Fourie, and E. Liu, "Towards intelligent mining for backfill: a genetic programming-based method for strength forecasting of cemented paste backfill," Minerals Engineering, vol. 133, pp. 69-79, 2019.

[108] M. D. Nguyen, B. T. Pham, L. S. Ho et al., "Soft-computing techniques for prediction of soils consolidation coefficient," CATENA, vol. 195, Article ID 104802, 2020.

[109] A. Goldstein, A. Kapelner, J. Bleich, and E. Pitkin, "Peeking inside the black box: visualizing statistical learning with plots of individual conditional expectation," Journal of Computational and Graphical Statistics, vol. 24, no. 1, pp. 44-65, 2015.

[110] D. V. Dao, H.-B. Ly, H.-L. T. Vu, T.-T. Le, and B. T. Pham, "Investigation and optimization of the C-ANN structure in predicting the compressive strength of foamed concrete," Materials, vol. 13, no. 5, p. 1072, 2020.

[111] C. Molnar, Interpretable Machine Learning, Lulu.com, Morrisville, NC, USA, 2019. 